\title{
Curing, Compatibility, and Fracture Toughness for Blends of Bismaleimide and a Tetrafunctional Epoxy Resin
}

\author{
KING-FU LIN* and JYH-CHIEN CHEN \\ Institute of Materials Science and Engineering \\ National Taiwan University \\ Taipei, Taiwan 10617, Republic of China
}

\begin{abstract}
The curing, compatibility, and fracture toughness of blends of 4,4'-bismaleimidodiphenylmethane (BDM)/tetraglycidyl diamino-diphenyl methane (TGDDM) were investigated. Diamino-diphenyl sulfone (DDS) was used as a curing agent. BDM alone could be both homopolymerized (at a lower temperature) and could also undergo Michael addition reactions with the primary amine of DDS. The secondary amine of DDS did not react with BDM. However, the network produced by homopolymerization was not miscible with that produced by the latter reactions. Curing of TGDDM with DDS took place almost at the same temperature as that of the homopolymerization of BDM, but well below the temperature of the Michael addition reaction. When a BDM/TGDDM mixture was cured with DDS in the stoichiometric ratio, the miscibility of the cured system increased with the amount of TGDDM. This was attributed to the fact that the network produced by Michael addition reactions was diminished. When DDS reacted entirely with TGDDM, the BDM/TGDDM/DDS cure yielded only a TGDDM/DDS network and a BDM homopolymerized network, which were not only miscible, but are also interpenetrating. The superior interpenetrated network, as indicated by the highest fracture toughness, was found at BDM $/ \mathrm{TGDDM}=40 / 60$ weight ratio in the BDM/TGDDM/ DDS curing systems.
\end{abstract}

\section{INTRODUCTION}

B ismaleimide (BMI) resins can provide a higher service temperature than epoxies, while maintaining epoxy-like processing. However, unmodified BMI after cure is extremely brittle because of a highly crosslinked structure. To improve toughness, the crosslink density of BMI was reduced by using a diamine as a chain extender (1-5). The diamine-modified BMI exhibits two types of cure reactions: one is the Michael addition of the diamine to the double bond in the maleimide groups; the other is the free radical polymerization of the double bonds (6).

Tetrafunctional epoxy resins are also brittle, although they have been used as a matrix for $>90 \%$ of aerospace composites (7). Numerous attempts have been made to increase the toughness of epoxy resins without sacrificing their high temperature properties. One such approach was the incorporation of polyetherimide and polyethersulfone to tetraglycidyl diaminodiphenyl methane/diaminodiphenyl sulfone

- To whom correspondence should be addressed.
(TGDDM/DDS) resin (8-10). However, the drawback of those attempts is that the processability is sacrificed, owing to the increased viscosity of the added thermoplastics. Recently, Woo et al. (11) reported that the TGDDM and 4,4'-bismaleimidodiphenylmethane (BDM) were miscible even after they were cured with DDS. Thus, we considered that their mixture after cure might have a higher fracture toughness than individual components, owing to the possible formation of interpenetrating networks.

Therefore, the curing, compatibility, and fracture toughness of BDM/TGDDM blends were investigated with DDS as a curing agent. It was found that their compatibility was strongly dependent on the amount of DDS reacting with BDM, which was not considered by Woo et al. in their study on the miscibility of TGDDM/BDM blends (11).

\section{EXPERMENTAL}

\section{Materials}

TGDDM epoxy was obtained from Ciba-Geigy with an epoxy equivalent weight ( $E E W$ ) of $125 \mathrm{~g} / \mathrm{mol}$, de- 
termined by the hydrochloric acid-methyl ethyl ketone method (12). DDS was also from Ciba-Geigy. BDM was prepared from maleic anhydride and 4,4'-diaminodiphenyl methane by the following method (13) with some modifications.

A solution of $4,4^{\prime}$-diaminodiphenyl methane $(0.5$ mol) in chloroform was added dropwise under nitrogen into a flask that had been charged with a solution of maleic anhydride (1.02 mol) at ice bath temperature. After the addition, the flask was stirred for $2 \mathrm{~h}$ at $25^{\circ} \mathrm{C}$. The resultant insoluble amic acid was filtered, washed with acetone, and dried under vacuum. Cyclization of the amic acid $(0.4 \mathrm{~mol})$ was carried out in an acetone solution containing acetic anhydride $(0.8$ mol), triethylamine ( $0.25 \mathrm{~mol})$, and nickel (II) acetate tetrahydrate $(0.025 \mathrm{~mol})$ at room temperature under nitrogen for $\sim 50 \mathrm{~h}$ until the BDM precipitated. The precipitate was then collected and washed with a sodium bicarbonate solution until free of acetic acid. The product was finally recrystallized from a $\mathrm{CHCl}_{3}$ / $\mathrm{MeOH}(1: 1)$ solution for purification.

\section{Sample Preparation}

$\mathrm{BDM} / \mathrm{DDS}$ mixtures were prepared by mixing the components in a melt state at $160^{\circ} \mathrm{C}$. For the preparation of $\mathrm{BDM} / \mathrm{TGDDM} / \mathrm{DDS}$ mixtures, BDM was mixed with TGDDM at $155^{\circ} \mathrm{C}$ first and then combined with DDS in 1:1 stoichiometry of amine hydrogen groups to the combined amount of double bonds in BDM and epoxy groups in TGDDM. All the mixtures were degassed at $160^{\circ} \mathrm{C}$ under vacuum before being cast in the mold for curing. Cure was done at $180^{\circ} \mathrm{C}$ for $2 \mathrm{~h}$ plus a post-cure period at $220^{\circ} \mathrm{C}$ for $10 \mathrm{~h}$.

\section{Analytical Techniques}

${ }^{13} \mathrm{C}$-nuclear magnetic resonance (NMR) spectra of $\mathrm{BDM}$ and its amic acid were recorded on a Bruker AM-300WB model NMR spectrometer with dimethyl sulfoxide-d6 (DMSO-d6) as a solvent and internal standard.

The phase transition and curing exotherm of BDM and all the mixed samples were measured by differential scanning calorimetry, using a DuPont 9900-910 model DSC. Tests were run at a heating rate of $10^{\circ} \mathrm{C} /$ min. Thermogravimetric analysis (TGA) of the samples was conducted in a Perkin-Elmer TGA-2 model thermogravimetric analyzer by heating from 50 to $800^{\circ} \mathrm{C}$ at a rate of $10^{\circ} \mathrm{C} / \mathrm{min}$. Dynamic mechanical analysis (DMA) of the cured samples was performed in a DuPont model $983 \mathrm{DMA}$, tested at a heating rate of $10^{\circ} \mathrm{C} /$ $\min$.

The fracture toughness of cured specimens was measured by compact tension specimen (CTS) techniques (14). The mold-cast rectangular CTS specimens were prepared with a precrack cut at a temperature $\sim 10^{\circ} \mathrm{C}>T_{g}$ (glass transition temperature) of the specimens by using a device described elsewhere (15). Fracture tests were performed in an Instron TM tensile tester at a cross-head speed of $0.5 \mathrm{~cm} / \mathrm{min}$. The value of the linear elastic strain energy release rate, $G_{I C}$, in $\mathrm{J} / \mathrm{m}^{2}$, was calculated from (16):

$$
G_{I C}=Y P_{C} a / E w b
$$

where $P_{\mathrm{C}}=$ load at crack initiation, $a=$ crack length, $E=$ flexural modulus of the specimens measured by the three-point bending test according to ASTM D-790, $w=$ width of the specimen, $b=$ thickness of the specimen, and $Y=$ the geometry factor given by:

$$
\begin{aligned}
Y= & 29.6-186(a / w)+656(a / w)^{2} \\
& -1017(a / w)^{3}+639(a / w)^{4}
\end{aligned}
$$

$G_{I C}$ values were averaged from six test specimens. Their fracture surface morphology was investigated by scanning electron microscopy (SEM). Samples for SEM were gold-sputtered and investigated in a Philips model SEM-515 scanning electron microscope.

\section{RESULTS AND DISCUSSION}

\section{Characterization of BDM/DDS Curing Systems}

Figure 1 shows the ${ }^{13} \mathrm{C}$-NMR spectra of the prepared BDM and its amic acid with the assignments of each carbon in the molecules [see Kumar et al., (17) and our previous study (13)]. The TGA thermogram of BDM shown in Fig. 2 indicates that the degradation temperature at 5 wt \% loss is $486^{\circ} \mathrm{C}$. BDM is a crystalline solid. Its DSC spectrum is shown in Fig. 3 with a sharp endothermic melting peak at $156^{\circ} \mathrm{C}$ and a broad exo-

(a)

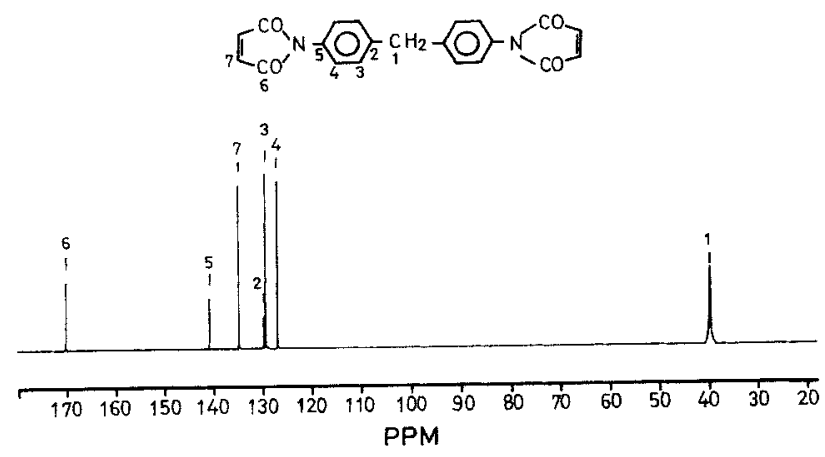

(b)
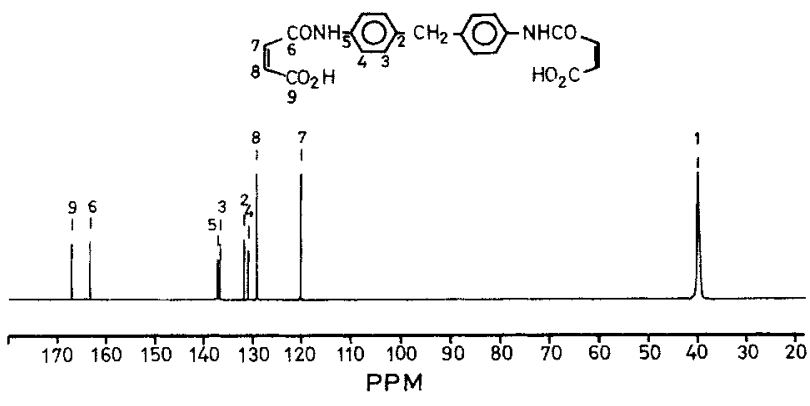

Fig. 1. ${ }^{13} \mathrm{C}-\mathrm{NMR}$ spectra of (a) the prepared BDM and (b) its amic acid. 


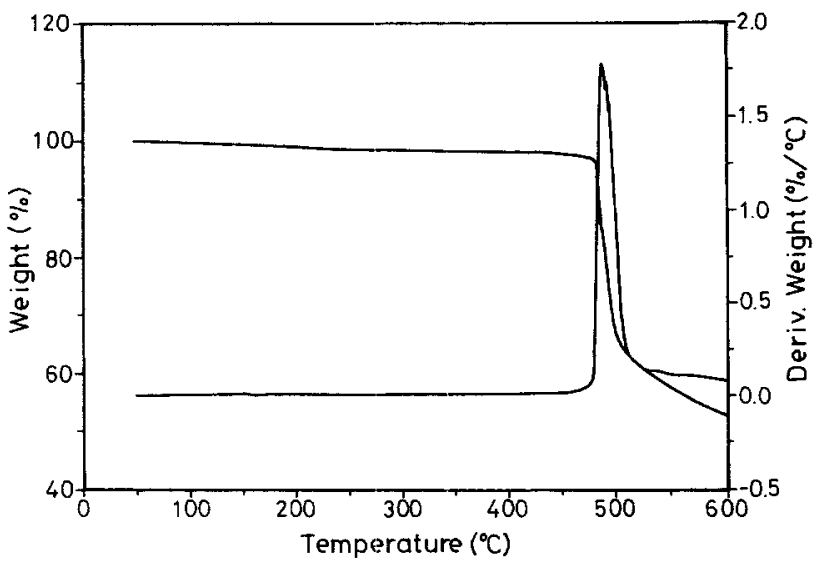

Fig. 2. TGA thermogram of the prepared BDM.

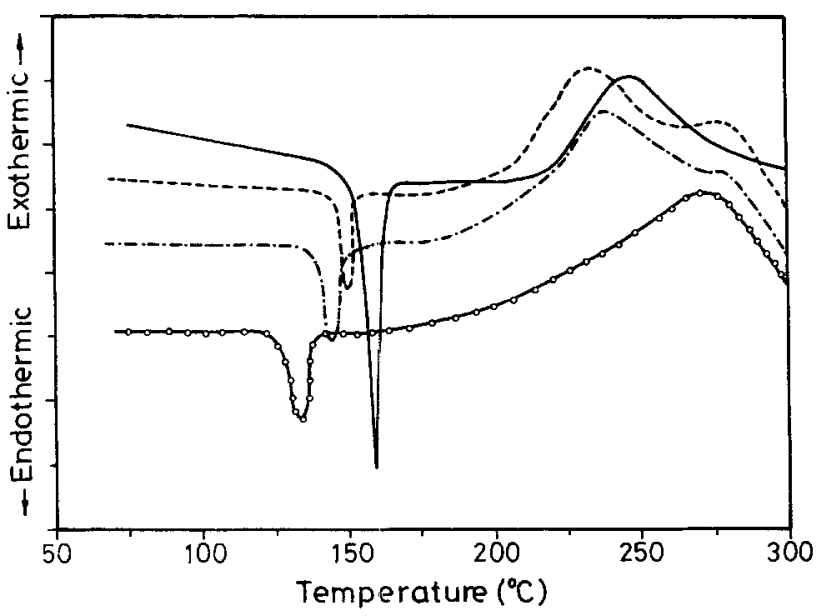

Fig. 3. DSC spectra of (-) BDM and its mixtures with the various molar ratios of DDS: $(---) 0.3,(-\cdot-) 0.5$, and (- 0 -) 1 .

thermic curing peak at $247^{\circ} \mathrm{C}$, the reaction of which has been well recognized as homopolymerization through the double bonds of the maleimide groups $(6$, $18,19)$.

As BDM was mixed with DDS, the melting point of the mixture was decreased with increasing molar ratio of DDS, as seen in Fig. 3. The molar ratio was defined as the moles of DDS divided by the moles of BDM. Since the melting point of DDS is $177^{\circ} \mathrm{C}$, higher than that of $\mathrm{BDM}$, the mixture is a eutectic mixture. On the other hand, when DDS was added to BDM in 0.3 molar ratio, the curing peak was divided into two peaks. The peak at the lower temperature was close to the original peak contributed by the homopolymerization of BDM. Thus, the peak at $273^{\circ} \mathrm{C}$ was believed to be a result of the Michael addition reaction between BDM and DDS, for the diamine-modified BMI has only two types of cure reactions (6).

When the molar ratio of DDS was increased to 0.5 , the DSC still showed two types of cure reactions, although the amount of the amine hydrogen groups is in a 1:1 stoichiometry with the double bonds of the maleimide groups in BDM. Until the molar ratio of DDS was increased to 1 , the two curing peaks merged into one peak at $270^{\circ} \mathrm{C}$. Since BDM and DDS formed a eutectic mixture, the curing peak should be due mainly to the Michael addition of primary amine hydrogen in DDS to the double bonds of maleimide groups in BDM. The reaction of secondary amine hydrogen groups would not be significant. Unpaired BDM monomers in the BDM/DDS eutectic mixture at 1:0.5 molar ratio tended to homopolymerize as indicated by DSC.

\section{Curing Behavior and Compatibility of BDM/TGDDM/DDS Formulations}

When $20 \mathrm{wt} \%$ TGDDM was mixed with BDM prior to cure with DDS, the exothermal cure peak at the higher temperature associated with the reactions of the primary amine with the double bonds of BDM became smaller, while that initially due to the BDM homopolymerization became broad (Fig. 4). The amount of DDS used in BDM/TGDDM/DDS formulations was stoichiometric in amine hydrogen with the combined amount of epoxy groups in TGDDM and double bonds in BDM. The BDM/TGDDM ( $80 / 20$ by wt) mixture cured with DDS was designated as the 80BDM/20TGDDM/DDS system, and so on. When the content of TGDDM was increased to $40 \mathrm{wt} \%$, the intensity of the peak initially due to the BDM homopolymerization increased while the previous peak at the higher temperature disappeared. Moreover, the temperature of the former peak is $225^{\circ} \mathrm{C}$, similar to that of the TGDDM/DDS reaction shown in Fig. 5, indicating that the homopolymerization of BDM was coincident with the curing of TGDDM/DDS. Apparently, the 60BDM/ 4OTGDDM/DDS system has the potential to produce a so-called simultaneous interpenetrating network (SIN), with two networks interlocking and exhibiting no, or insignificant, chemical bonding (20).

The homogeneity of the network cured by BDM/ TGDDM/DDS formulations was studied by DMA and SEM. Figure 6 shows the loss modulus spectra of cured BDM/DDS, 80BDM/20TGDDM/DDS, and

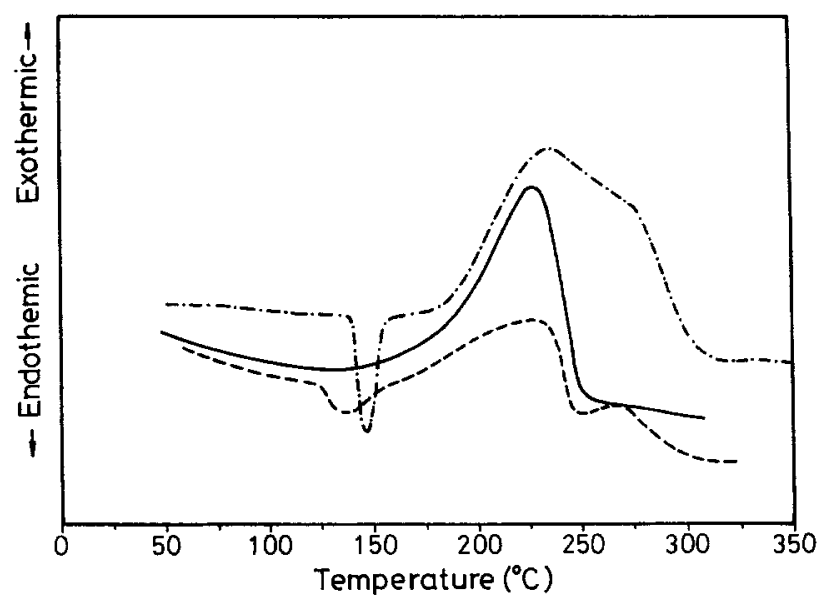

Fig. 4. DSC spectra of (- - - $)$ BDM/DDS, (- - ) 80BDM/ 2OTGDDM/DDS, and (-) 6OBDM/4OTGDDM/DDS. 


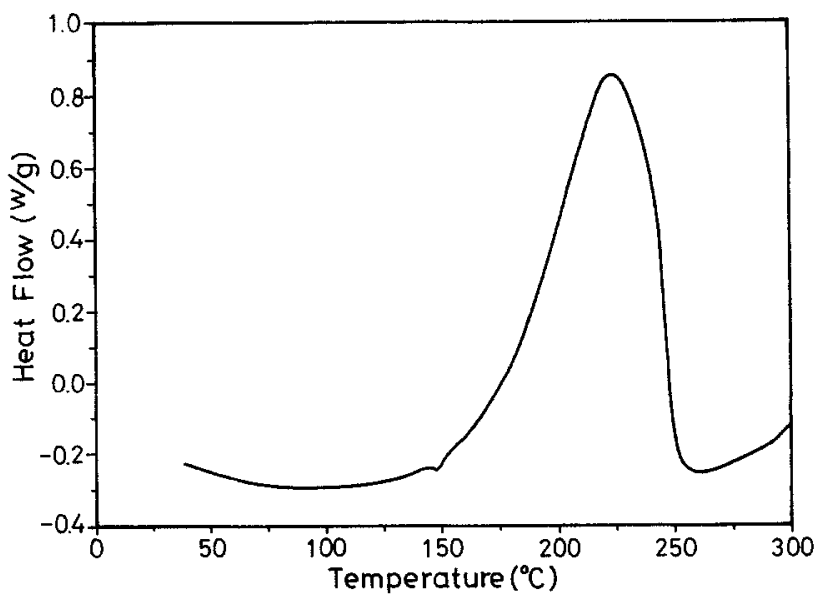

Fig. 5. DSC spectrum of the TGDDM/DDS epoxy resin.

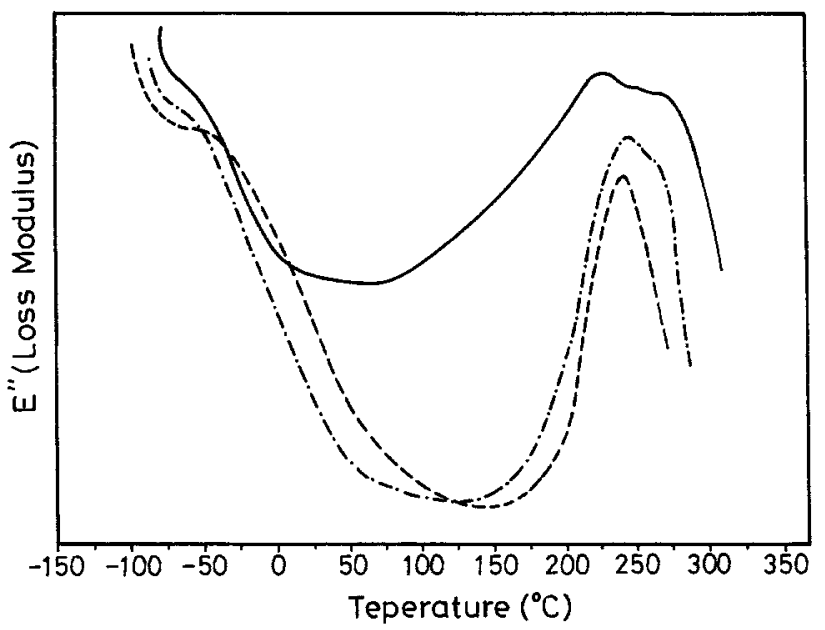

Fig. 6. Loss modulus spectra of the cured (-) BDM/DDS, $(-\cdots) 80 B D M / 20 T G D D M / D D S$, and (- - ) 60BDM/4OTG$D D M / D D S$.

60BDM/40TGDDM/DDS systems. The glass transition, $T_{g}$, of cured BDM/DDS (1:0.5 molar ratio) has two peaks in its loss modulus spectrum. The peak at the lower temperature $\left(223^{\circ} \mathrm{C}\right)$ was due to the $T_{g}$ of the linear polymeric portion of BDM reacting with the primary amine of DDS because the $T_{g}$ is close to that of the cured BDM/DDS in 1:1 molar ratio. Thus, the peak at $273^{\circ} \mathrm{C}$ was due to the $T_{g}$ of the homopolymerized network of BDM, although its curing temperature is lower than that of BDM reacting with the primary amine of DDS. Apparently, its higher $T_{g}$ resulted from the higher crosslinking network produced by BDM homopolymerization. When 20 wt\% TGDDM was mixed with BDM and then.cured with DDS, the glass transition peak at the lower temperature shifted significantly to the higher temperature, resulting from the fact that the amount of network contributed by the $\mathrm{BDM} / \mathrm{DDS}$ reaction was decreased. When the amount of TGDDM was increased to $40 \mathrm{wt} \%$, only one $T_{g}$ appeared, as seen in Fig. 6. Since the TGDDM/DDS curing reaction and BDM homopolymerization in the 60BDM/40TGDDM/DDS formulation took place si- multaneously, a single $T_{g}$ is consistent with their networks' being interpenetrating. When the content of TGDDM was $>40 \mathrm{wt} \%$, their cured BDM/TGDDM/ DDS resins remained at a single $T_{g}$, whose temperature vs. the content of TGDDM is shown in Fig. 7 .

The curing reaction of TGDDM itself took place at $308^{\circ} \mathrm{C}$, with a curing exotherm of $921 \mathrm{~J} / \mathrm{g}$ (Fig. 8), whereas the homopolymerization of BDM itself took place at $246^{\circ} \mathrm{C}$ with a curing exotherm of $169 \mathrm{~J} / \mathrm{g}$ (Fig. $3)$. The major curing peak of the TGDDM/BDM $(40 / 60$ by wt) mixture at $302^{\circ} \mathrm{C}$ has an exotherm of $355 \mathrm{~J} / \mathrm{g}$ (Fig. 6) and has $\sim 40 \%$ the area of curing peak as TGDDM itself, indicating that curing of the TGDDM was not influenced by the BDM. In other words, no apparent copolymerization of TGDDM and BDM took place during cure of the TGDDM/BDM mixture. Since BDM barely reacted with both DDS and TGDDM in the 60BDM/40TGDDM/DDS curing system, the network formed by the BDM homopolymerization would have insignificant chemical bonding to the TGDDM/DDS cured networks.

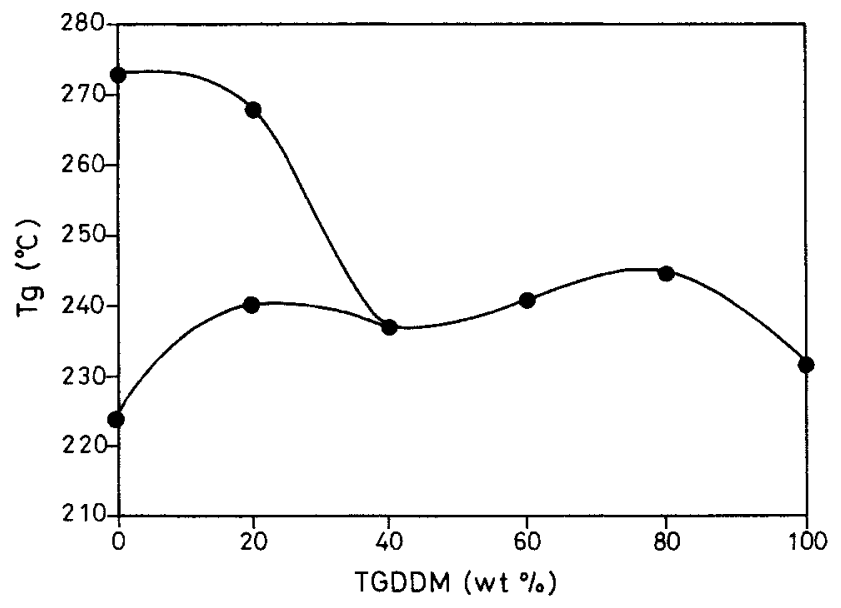

Fig. 7. Glass transition temperature ( $T g$ ) of the cured BDM/ TGDDM/DDS us. the wt\% TGDDM.

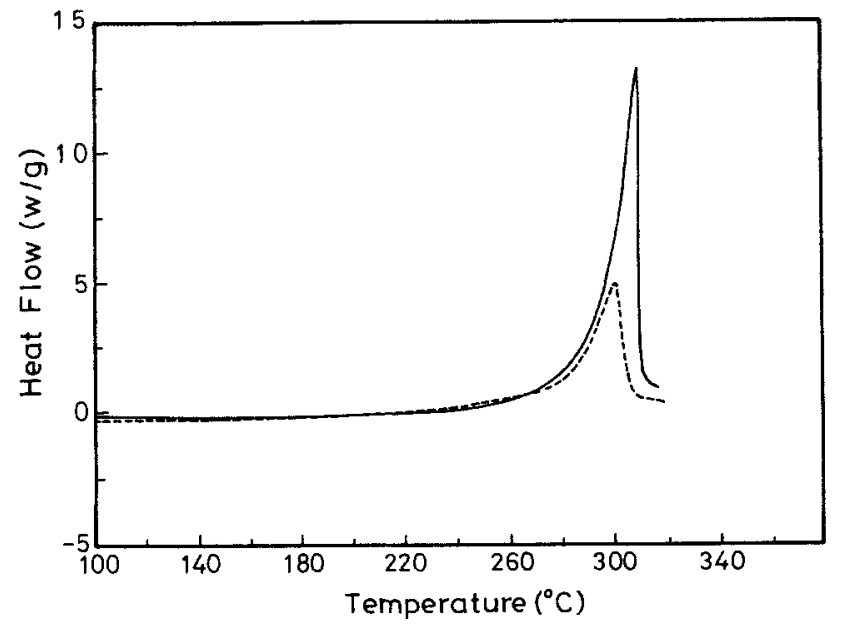

Fig. 8. DSC spectra of $(-)$ TGDDM and $(---)$ its mixture with $B D M$ in $40: 60$ by weight. 
By the above comments, curing of the BDM/TGDDM/DDS resin systems consisted of the TGDDM/ DDS reactions, the reactions between $B D M$ and the primary amine of DDS, and the BDM homopolymerization. The primary amine of DDS reacted with TGDDM faster than its secondary amine and reacted at a lower temperature than with BDM. If the amount of the primary amine in DDS were greater than the epoxy groups in TGDDM, the excess primary amine would react with $B D M$ at a higher temperature. Therefore, we assumed that the content of BDM in BDM/TGDDM/ DDS after subtracting the amount for the BDM/DDS reaction was entirely subjected to homopolymerization. The weight percentage of networks contributed by BDM reacting with the primary amine, by BDM homopolymerization, and by TGDDM reacting with DDS individually could be calculated. The results are listed in Table 1. As seen in the Table, the weight percentage of network contributed by BDM reacting with the primary amine decreased from 63 to $31.4 \%$ when BDM was mixed with $20 \mathrm{wt} \%$ TGDDM. As the amount of TGDDM was increased to $40 \mathrm{wt} \%$, the content of the former network further decreased to $1.2 \%$. The results are qualitatively supported by the DMA results shown in Fig. 6, which indicated that the $T_{g}$ peak associated with the BDM reacting with the primary amine of DDS became smaller and shifted to a higher temperature when $20 \mathrm{wt} \%$ TGDDM was mixed with BDM.

When the content of TGDDM in BDM/TGDDM/ DDS was $\geq 60 w t \%$, the secondary amine would participate in the curing reaction with the TGDDM. The percentage of epoxy groups in TGDDM that reacted with the primary amine and secondary amine of DDS was calculated individually, and the results are also listed in Table 1. As the content of TGDDM in BDM/ TGDDM/DDS was increased, more epoxy groups re- acted with the secondary amine groups, resulting in higher crosslinking density in the TGDDM/DDS network. This explains the increased $T_{g}$ of the cured BDM/TGDDM/DDS with the content of TGDDM until $80 \mathrm{wt} \%$ was reached (Fig. 7).

\section{Fracture Toughness and Morphology of Cured BDM/TGDDMDDS Systems}

The fracture toughness, indicated by the strain energy release rate, $G_{I C}$, of cured BDM/TGDDM/DDS systems as a function of the content of TGDDM, is plotted in Fig. 9. As seen in the Figure, the 40BDM/ 60TGDDM/DDS system had the highest fracture toughness, $\sim 2.7$ times that of BDM/DDS and 3.5 times that of TGDDM/DDS resins. Figure 10 shows the fracture surfaces of various BDM/TGDDM/DDS CTS specimens in the fracture initiation region observed by SEM. For the BDM/DDS and 80BDM/ 20TGDDM/DDS systems, their fracture surfaces showed a heterogeneous structure with submicron domains dispersed in the matrix. These inhomogeneous morphologies are consistent with the DMA results (Fig. 6), suggesting that the network of BDM reacting with the primary amine of DDS is incompatible with the BDM-homopolymerized network and the TGDDM/DDS network. When the content of TGDDM was $\geq 40 \mathrm{wt} \%$, there was almost no network of BDM reacting with the primary amine of DDS. In addition, the BDM-homopolymerized network and the TGDDM/ DDS network were interpenetrating. Thus, the fracture surface of BDM/TGDDM/DDS systems became more homogeneous as seen in Fig. 10. The lower fracture toughness for the BDM/DDS and 80BDM/20TGDDM/DDS systems compared to the 60BDM/40TGDDM/DDS and 40BDM/60TGDDM/DDS is believed to result from their incompatible networks. On the

Table 1. The Weight Percentage of the Networks in the Cured BDM/TGDDM/DDS Resins Contributed by BDM Reacting With the Primary Amine, BDM Homopolymerization, and TGDDM/DDS Reactions Individually.

\begin{tabular}{|c|c|c|c|c|}
\hline \multirow[b]{2}{*}{$\begin{array}{l}\text { TGDDM Content, wt\%, } \\
\text { in BDM/TGDDM/DDS } \\
\text { Formulations }\end{array}$} & \multicolumn{4}{|c|}{ Wt $\%$ of Networks Produced by } \\
\hline & $\begin{array}{l}\text { BDM Reacting With } \\
\text { Primary Amine }\end{array}$ & BDM Homopolymerization & $\begin{array}{l}\text { TGDDM/DDS } \\
\text { Reactions }\end{array}$ & $\frac{\mathbf{P}^{\star}, \%}{\mathbf{S}^{* *}, \%}$ \\
\hline 0 & 63 & 37 & 0 & $\begin{array}{l}0 \\
0\end{array}$ \\
\hline 20 & 31.4 & 39.5 & 21.1 & $\begin{array}{r}100 \\
0\end{array}$ \\
\hline 40 & 1.2 & 41.8 & 57 & $\begin{array}{r}100 \\
0\end{array}$ \\
\hline 60 & 0 & 28 & 72 & $\begin{array}{l}73 \\
27\end{array}$ \\
\hline 80 & 0 & 13 & 87 & $\begin{array}{l}59 \\
41\end{array}$ \\
\hline 100 & 0 & 0 & 100 & $\begin{array}{l}50 \\
50\end{array}$ \\
\hline
\end{tabular}

\footnotetext{
- Mol\% of epoxy groups in TCDDM reacted with the primary amine.
}

* Mol\% of epoxy groups in TCDDM reacted with the secondary amine. 


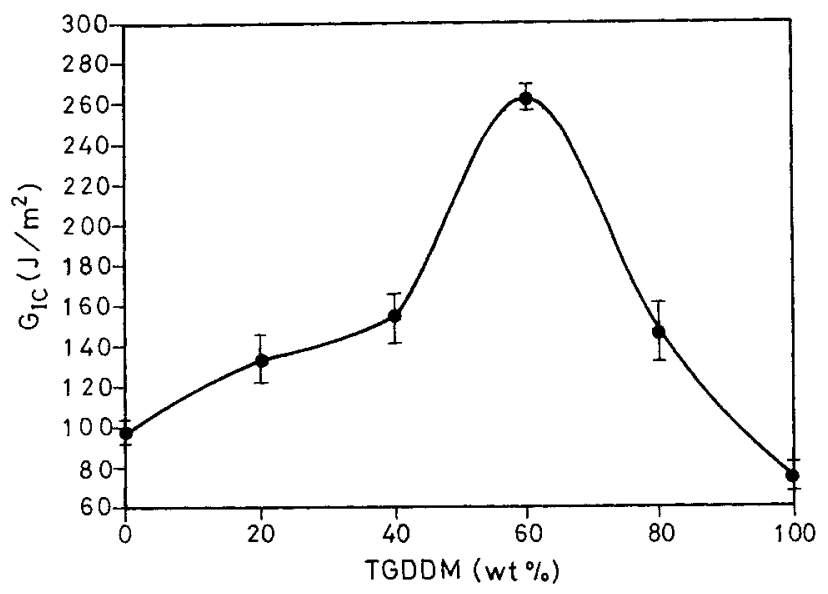

Fig. 9. $G_{I C}$ of the cured BDM/TGDDM/DDS vs. the $w t \%$ TG$D D M$.

other hand, the highest fracture toughness for 40BDM/60TGDDM/DDS compared to 60BDM/ 40TGDDM/DDS and 20BDM/80TGDDM/DDS indicates that its interpenetrating network is superior. In

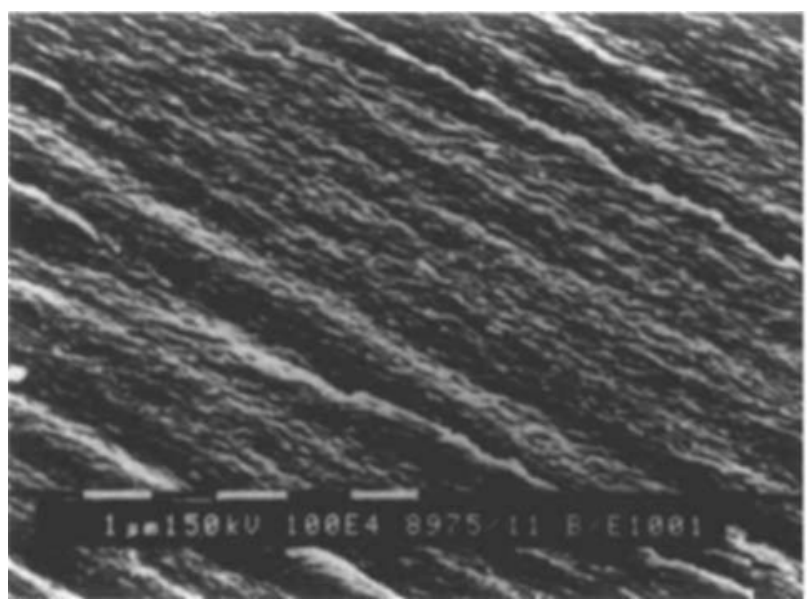

A

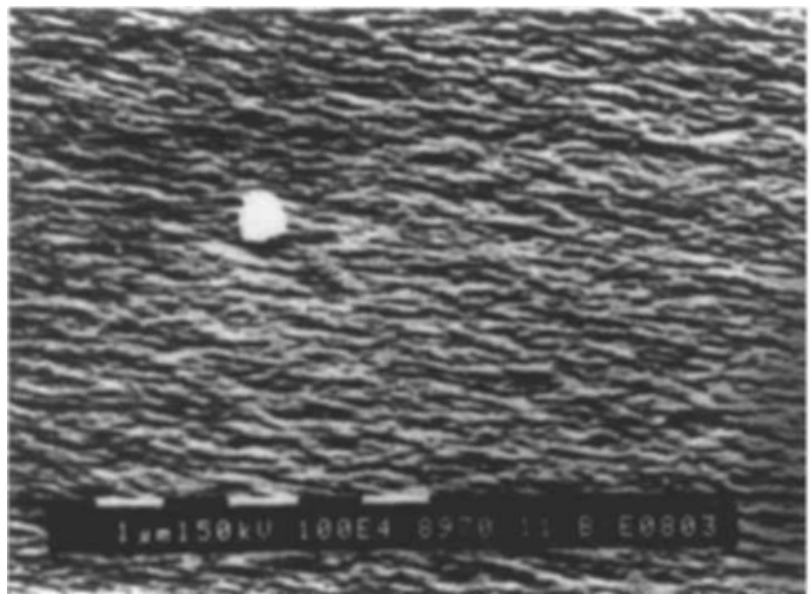

B addition, TGDDM/DDS epoxy resin had the lowest fracture toughness and the lowest $T_{g}$ among the BDM/TGDDM/DDS systems. Therefore, the addition of BDM to TGDDM/DDS does not only increase the fracture toughness but also increases its service temperature.

The degradation temperature of $\mathrm{BDM}$ was significantly decreased by the addition of DDS. Because of the difficulty of determining the degradation temperature of the samples in the TGA thermograms from the inception of degradation curves, it was measured at 5 wt\% loss of the materials. Figure 11 shows the degradation temperature of cured BDM/DDS resins as a function of the molar ratio of DDS. The decrease of degradation temperature with the content of DDS was due to the fact that the - $\mathrm{C}-\mathrm{N}$-C groups produced by the Michael addition reaction were easier to split compared to the network produced by BDM homopolymerization. When BDM was reacted with DDS in a stoichiometric ratio, i.e. 1:0.5 molar ratio, the degradation temperature was decreased from 483 to $342^{\circ} \mathrm{C}$. However, when 20 wt\% TGDDM was mixed with BDM

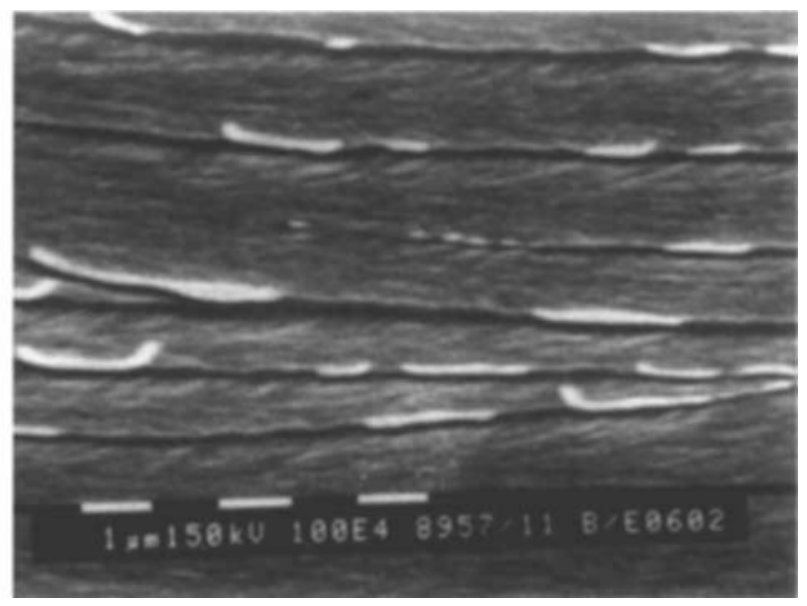

C

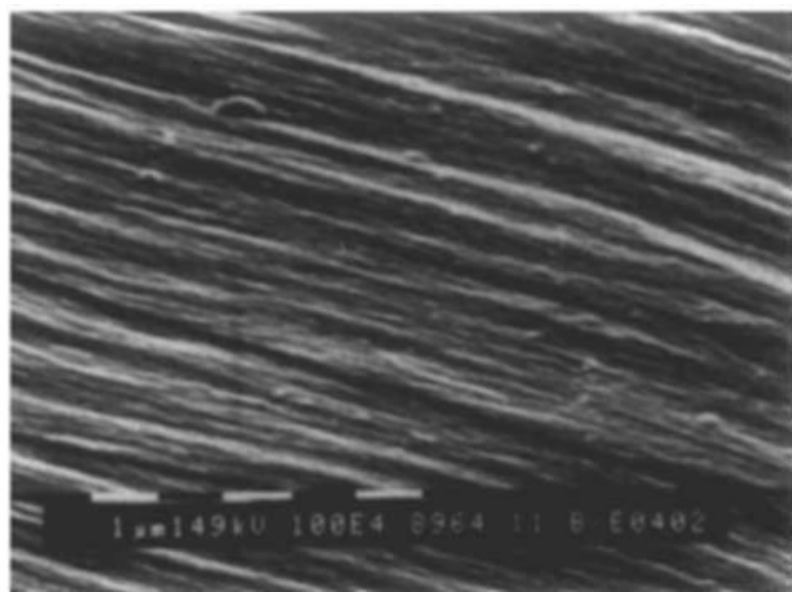

D

Fig. 10. SEM photographs of the fracture surface of cured (a) BDM/DDS, (b) 8OBDM/20TGDDM/DDS, (c) 6OBDM/4OTGDDM/DDS, and (d) $40 B D M / 6 O T G D D M / D D S$. 


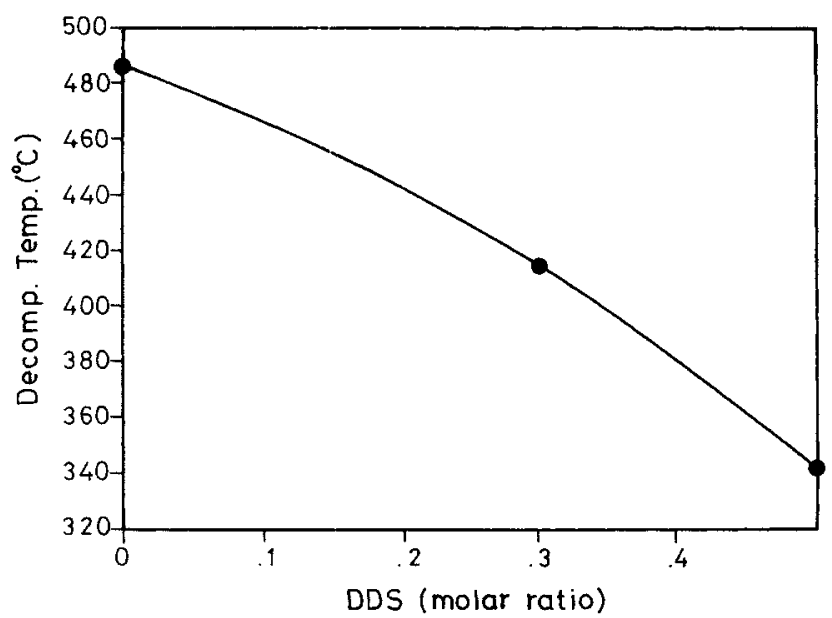

Fig. 11. Degradation temperature of the cured BDM/DDS as a function of the molar ratio of DDS.

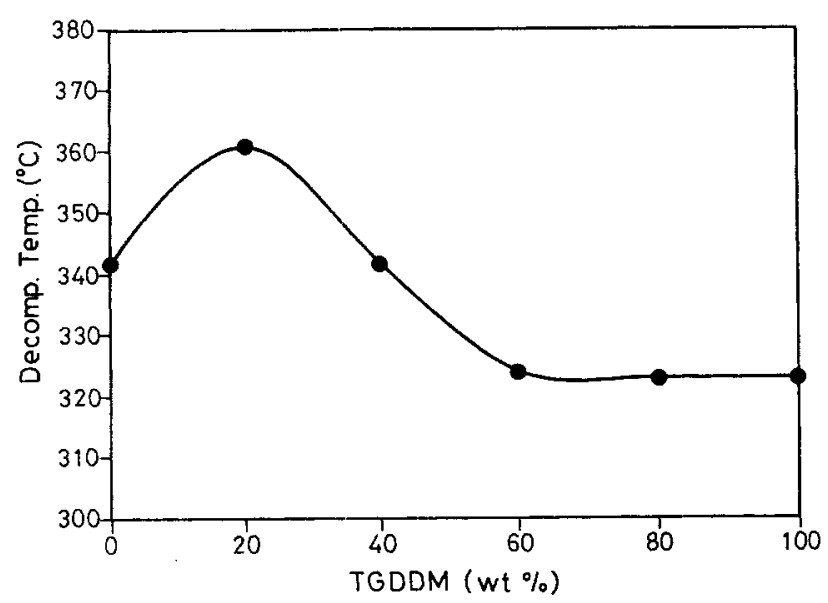

Fig. 12. Degradation temperature of the cured BDM/TGDDM/ DDS as a function of the wt\% TGDDM.

prior to cure with DDS, the degradation temperature was increased to $361^{\circ} \mathrm{C}$ (Fig. 12). The increased degradation temperature is believed to result from the increased content of the BDM-homopolymerized network with a decrease in the content of BDM reacting with the primary amine (Table 1). When the content of TGDDM was increased to $40 \mathrm{wt} \%$, the degradation temperature of the BDM/TGDDM/DDS resin systems decreased again. It was due to the fact that the content of network contributed by the TGDDM/DDS reactions was increased. When the content of TGDDM was $\geq 60$ $w t \%$, the trend of decreasing degradation temperature leveled off and its temperature became close to that of TGDDM/DDS (Fig. 12).

\section{CONCLUSIONS}

BDM and DDS form a eutectic mixture during mixing. During cure, BDM can react only with the primary amine of DDS or homopolymerize by itself. When BDM is reacted with DDS at 0.5 molar ratio, the network produced by the BDM reacting with DDS is immiscible with that produced by BDM homopolymerization. Both $T_{g}$ and the degradation temperature of the BDM/ DDS cured network are lower than those of the BDM homopolymerized network.

In the BDM/TGDDM/DDS curing systems, the miscibility of the networks increases with the amount of TGDDM. The TGDDM/DDS curing reaction and BDM homopolymerization take place simultaneously but have no inter-reaction. Thus, if the system has no $\mathrm{BDM} / \mathrm{DDS}$ reaction involved, the TGDDM/DDS cured network and BDM homopolymerized network are miscible and form a so-called simultaneous interpenetrating network (SIN). Among the BDM/TGDDM/DDS curing systems, 40BDM/60TGDDM/DDS cured resin has a superior SIN structure, as indicated by the highest fracture toughness and the homogeneous fracture surface. The addition of BDM to the TGDDM/DDS curing system not only increases the fracture toughness but also increases its service temperature.

\section{ACKNOWLEDGMENT}

Financial support of this work by the National Science Council in Taiwan, R.O.C., through Grant NSC81-0405-E002-09 is gratefully acknowledged.

\section{REFERENCES}

1. J. V. Crivello, J. Polym. Sci., Polym. Chem. Ed., 11, 1185 (1973).

2. I. K. Varma, G. M. Fohlen, and J. A. Parker, J. Polym. Sci. Polym. Chem. Ed., 20, 283 (1982).

3. D. K. Kumar, G. M. Fohlen, and J. A. Parker, J. Polym. Sci., Polym. Chem. Ed., 21, 245 (1983).

4. I. K. Varma, Sangita, and D. S. Varma, J. Polym. Sci., Polym. Chem. Ed., 22, 1419 (1984).

5. C. D. Giulio, M. Gautier, and B. Jasse, J. Appl. Polym. Sci., 28, 1771 (1984).

6. J. M. Margolis, Ed., Advanced Thermal Composites, Industrial and Commercial Applications, p. 18, Van Nostrand Reinhold Co., New York (1986).

7. P. J. Mooney, Inter. SAMPE Tech. Conf. Ser. 21, 37 (1989).

8. C. B. Bucknall and A. H. Gilbert, Polymer, 30, 213 (1989).

9. C. B. Bucknall and I. K. Partridge, Polymer, 24, 639 (1983).

10. J. Diamont and R. J. Moulton, Natl SAMPE Symp. 29, 422 (1984).

11. E. M. Woo, L. B. Chen, and J. C. Seferis, J. Mater. Sci., 22, 3665 (1987).

12. H. Lee and K. Neville, Handbook of Epoxy Resins, pp. 4-14, McGraw-Hill, New York (1967).

13. K.-F. Lin and J.-S. Lin, J. Appl. Polym. Sci., 50, 1601 (1993).

14. K.-F. Lin, W.-Y. Shu, and T.-L. Wey, Polymer, 34, 277 (1993).

15. S. A. Thompson and R. J. Farris, SAMPE J., 24, 47 (1988).

16. R. Y. Ting and R. L. Cottington, J. Appl. Polym. Sci., 25, 1815 (1980).

17. D. Kumar, G. M. Fohlen, and J. A. Parker, J. Polym. Sci., Polym. Chem. Ed., 21, 245 (1983).

18. K. N. Ninan, K. Krishnan, and J. Mathew, J. Appl. Polym. Sci., 32, 6033 (1986).

19. I. K. Varma, S. P. Gupta, and D. S. Varma, J. Appl. Polym. Sci., 33, 151 (1987).

20. O. Olabish, L. M. Robeson, and M. T. Shaw, PolymerPolymer Miscibility, p. 11, Academic Press, New York (1972). 